ISSN : 2252-3839 (Print)

ISSN : 2549-2403 (On Line)

DOI : 10.28989/compiler.v9i1.666

http://ejournals.stta.ac.id/index.php/compiler/

\title{
SENDING DRONE FLYING SPEED DATA USING ANDROID-BASED CLIENT SERVER METHOD
}

\author{
Daewu Gus Bintara Putra', Anggraini Kusumaningrum ${ }^{2}$ \\ ${ }^{1,2)}$ Program Studi Teknik Informatika, Departemen Informatika, \\ Sekolah Tinggi Teknologi Adisutjipto \\ Jl. Janti, Blok R Lanud Adisutjipto Yogyakarta \\ Email : 1daewu.bintara1996@gmail.com,2anggraini@stta.ac.id
}

\begin{abstract}
Abstract - Drones as Unmanned Aerial Vehicle that are controlled using remote control are experiencing better development. The speed of the drone that cannot be accessed on the remote control can be determined through a client-server based application. The client side application, named Mydrone, is placed on the drone while on the server side, named Admin Drone, on earth. Mydrone and Admin Drone are applications made in this research based on andorid. This application on the client and server is used to monitor the speed of flying drones by using the Google Play Service library. Data sent from the client to the server in realtime by using Google Firebase. From the tests carried out it can be seen the speed of the drone when flying horisontal ly, while when flying vertically the speed is not detected. Battery capacity will also decrease when the speed of the drone gets faster, this is seen in the data when the speed is $8,741 \mathrm{~km} / \mathrm{h}$, the electricity demand taken from the battery is $31 \%$.
\end{abstract}

Keyword: Drones, Google Play Service, Flying Speed.

\section{Latar Belakang Masalah}

Kendaraan udara tak berawak sudah banyak dibuat oleh pabrikan dari luar negeri dan dalam negeri mengalami perkembangan yang yang cukup baik dengan penambahan feature dari produk ke produk lainya. Kendaraan udara tak berawak juga dikenal dengan nama as Unmanned Aerial Vehicle (UAV), ada juga yang memberi nama sebagai drone, dan quad copter yang terbang dengan kendali terbanya menggunakan remote control. Drone dapat membawa beban saat terbang, beban yang dibawa ini sesuai dengan kebutuhan yang diinginkan oleh pengendali drone, salah satunya membawa smartphone berbasis android untuk mengambil gambar[1] dan mendata posisi koordinat terbang[2] menggunakan metode client server dengan aplikasi sisi client menggunakan smartphone dan sisi server menggunakan komputer jinjing. Drone yang diterbangkan secara remote memiliki jarak terbang dapat dikendalikan[3] dan kecepatan terbangnya juga dapat dikendalikan[4]. Kecepatan drone sama halnya kecepatan kendaraan yang berjalan didarat. Kecepatan sebuah kendaraan dapat diukur dan dipantau menggunakan OpenCV[5], real time dengan android[6], instant messaging di android[7], pengolahan video[8], sensor magnetic[9], motion vector[10] dan dapat juga menggunakan perpaduan antara teknik rektifikasi citra dan tapis kalman[11].

Kecepatan terbang drone saat terbang horisontal atau vertikal dibaca menggunakan layanan yang disediakan pada Google Plays Service. Tools getSpeed adalah sebuah fungsi yang disediakan oleh Android dan dibuat oleh perusahaan Google yang mana berfungsi untuk mendapatkan kecepatan device yang menggunakan fungsi tersebut. Tools location merupakan fungsi yang disediakan oleh oleh Google untuk mendapatkan letak akurasi geografis longitude dan latitude (Google Developers). Kecepatan yang didapatkan dengan cara seperti itu, dikirmkan dari sisi client yang dibawa terbang drone ke sisi server yang ada dibumi. Metode client server antara dua peralatan dengan memanfaat perangkat smartphone berbasis 
android dengan memanfaatkan jaringan wifi[12], pada penelitian ini hanya untuk one to one antara drone dengan kendali dibumi menggunakan jaringan internet, dan data yang dikirimkan memanfaatkan fasilitas yang ada pada firebase[13][14]. Pada penelitian ini, kecepatan terbang drone digunakan untuk mengetahui seberapa besar pengaruh kecepatan terbang drone terhadap kapasitas baterai, sehingga proses pembuatan drone rakitan bisa lebih maksimal.

\section{Metodologi Penelitian}

Metode penelitian yang digunakan dan dilakukan dalam penelitian ini, seperti terlihat pada Gambar 1, dengan merancang perangkat lunak terlebih dahulu. Perangkat lunak ini ada dua jenis, sisi client dan sisi server. Perangkat lunak sisi client ditempatkan ada smartphone berbasis android yang dibawa terbang oleh drone, sedangkan perangkat lunak sisi server ditempatkan pada smartphone yang ada dibumi, Setelah perangkat lunak selesai dirancang dan dibuat, selanjutnya dilakukan pengujian untuk mendapatkan data kecepatan dan mengirimkannya dari client ke server memanfaatkan firebase.

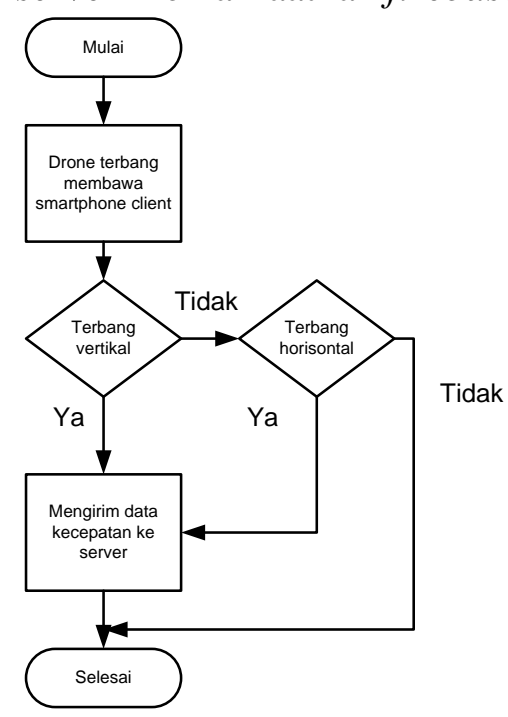

Gambar 1. Metode penelitian yang dilakukan

\section{A. Use case diagram}

Pada perancangan use case diagram aplikasi terdapat dua desain use case diagram, yaitu perancangan untuk aplikasi Sisi Client dan aplikasi Sisi Server.

1. Use case diagram aplikasi Sisi Client. lihat Gambar 2, dijelaskan bahwa user bisa mengaktifkan fungsi send data real-time dan menonaktifkannya setelah user berhasil login pada aplikasi.

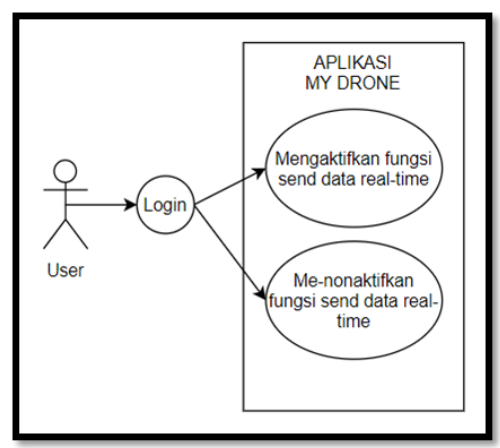

Gambar 2. Use Case Diagram aplikasi Sisi Client

2. Use case diagram aplikasi Sisi Server, lihat Gambar 3, user bisa membuat data drone baru, menghapus data drone, monitoring drone yang telah diaktifkan fungsi send data 
real-time nya, menyimpan data monitoring, melihat data drone dan mengubah foto profil. Semua fungsi tersebut bisa dilakukan apabila user telah terdaftar dan berhasil login aplikasi.

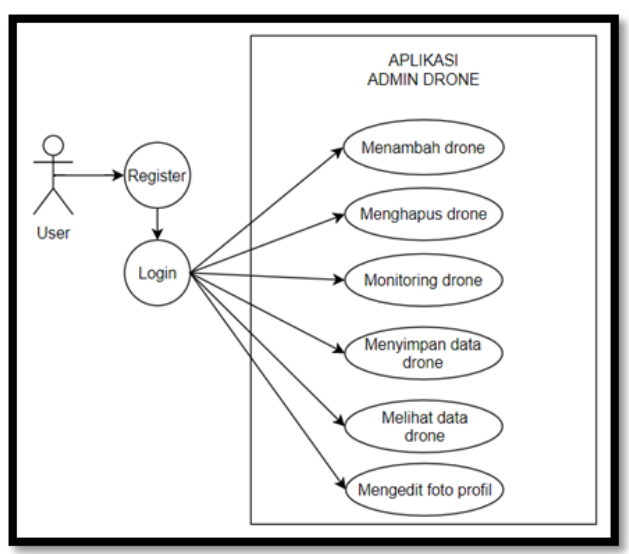

Gambar 3. Use Case Aplikasi Sisi Server

\section{B. Sequence diagram}

Pada sequence diagram aplikasi terdapat dua sequence diagram, yaitu sequence diagram untuk aplikasi Sisi Client dan aplikasi Sisi Server.

1. Sequence diagram sisi Client, lihat Gambar 4, user saat pertama kali menjalankannya akan muncul tampilan splash dan dilanjutkan ke tampilan login untuk memasukan dengan memasukan email, kemudian akan masuk ke bagian utama dan pengirman data kecepatan, sehingga saat dibawa terbang akan membaca dan mengirmkan data ke sisi server.

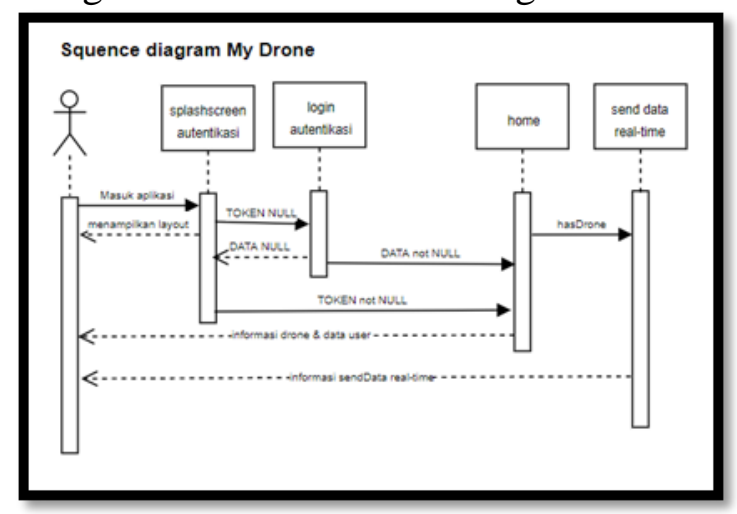

Gambar 4. Sequence Diagram Sisi Client

2. Sequence diagram sisi Server, lihat Gambar 5, user yang mengaktifkan aplikasi sisi server yang ada pada smartphone yang tidak dibawa terbang drone akan masuk pada tampilan splass dan login, hamper sama dengan sisi client, jika belum register diwajibkan untuk register terlebih dahulu. Jika sudag melewati login maka tampilan selanjutnya adalah data yang ditampilkan dari proses pengiriman oleh sisi client. 


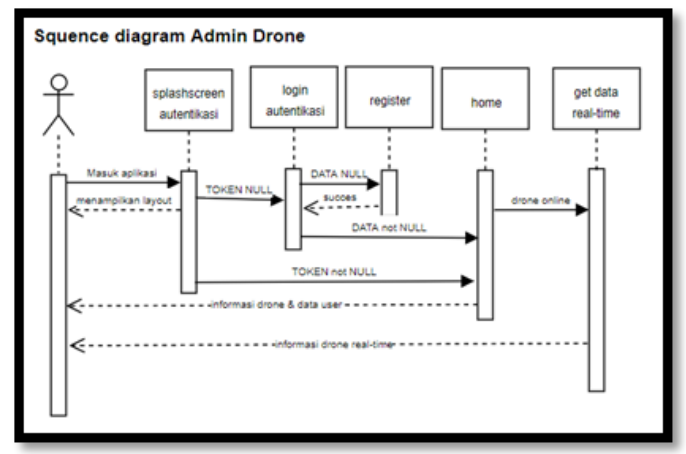

Gambar 5. Squence Diagram Sisi Server

\section{Hasil dan Pembahasan}

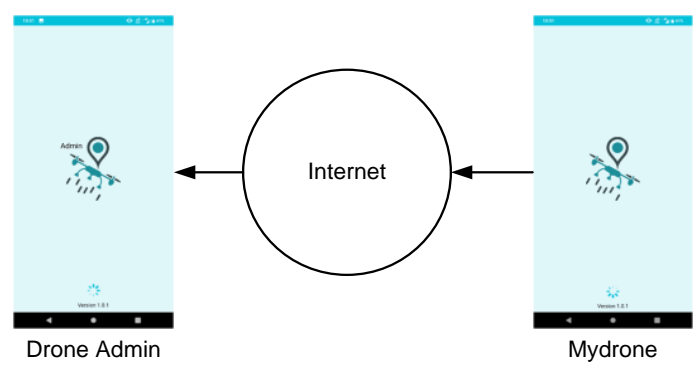

Gambar 6. Hubungan Client Server antar aplikasi

Tidak seperti penelitian sebelumnya, dimana aplikasi sisi client berupa smartphone dan sisi server berupa komputer[1][2], pada penelitian ini dihasilkan perangkat lunak client-server yang dipasangkan pada dua buah smartphone. Setelah perancangan dilakukan terhadap aplikasi sisi client atau sisi server seperti terlihat pada Gambar 6, selanjutnya pengujian untuk drone terbang naik turun atau terbang vertikal, drone terbang maju atau terbang horisontal dan perbandingan terbang menggunakan drone, dan dibawa menggunakan sepeda motor.

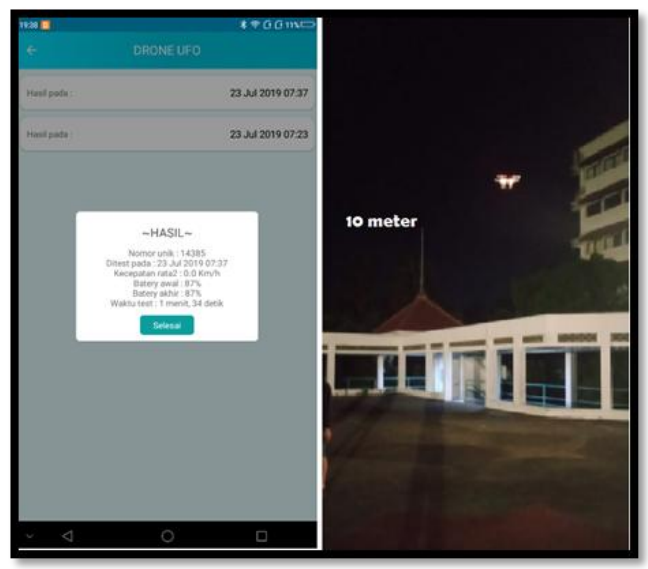

Gambar 7. Percobaan drone vertikal naik 10 meter

Pada Gambar 7, terlihat drone pada ketinggian kurang lebih 5 meter dengan acuan antena pencakar langit gedung seperti pada gambar dimana ketinggian antena tersebut 10 meter. Sehingga dapat ditentukan ketinggian drone terbang dengan menerbangkan drone setinggi antena pencakar langit. Didapat hasil kecepatan terbang rata-rata $0.0 \mathrm{~km} / \mathrm{h}$ dalam waktu terbang 1 menit 33 detik. Hal ini menunjukan bahwa saat drone terbang vertikal, Mydrone tidak mampu membaca kecepatan dengan menggunakan fungsi getspeed yang 
tersedia di Google Play Service. Sehingga data kecepatan yang dikirimkan dari client ke server $0.0 \mathrm{~km} / \mathrm{h}$. Sedangkan data kapasitas baterai drone berkurang dan sukses dikirimkan secara client-server. Sehingga untuk penelitian selanjutnya, bisa di selesaikan dengan menggunakan persamaan mencari kecepatan dimana kecepatan dihasilkan dari jarak/ waktu, dengan terlebih dahulu melakukan pengecekan apakah drone tersebut terbang secara vertical atau horizontal. Untuk mengetahui apakah drone tersebut terbang secara vertical atau horizontal dengan menggunakan data perpindahan koordinat longitude dan lalitude drone.

Pengujian selanjutnya drone terbang secara horisontal, dengan perbedaan kecepatan terbang dari kecepatan rendah hingga kecepatan tinggi dengan drone DJI SPARK seperti terlihat pada Gambar 8.

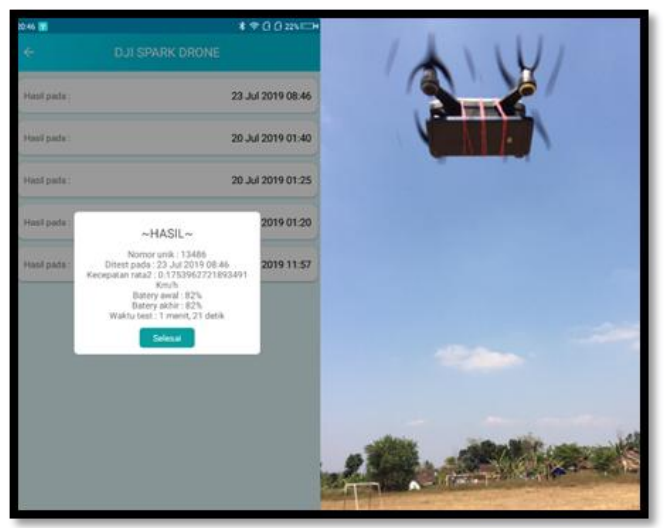

Gambar 8. Drone terbang secara horisontal.

Pada saat drone terbang membawa muatan smartphone yang didalamnya ada aplikasi Mydrone, diuji dengan jarak terbang yang berbeda-beda dan kecepatan juga berbeda, ini dilakukan untuk melihat pengaruh kecepatan terhadap kapasitas penyimpanan baterai yang ada pada drone. Hasil pengujian ini selengkapnya dapat dilihat pada tabel 1.

Tabel 1. Hasil pengujian terbang horisontal

\begin{tabular}{cccc}
\hline No & $\begin{array}{c}\text { Jarak Terbang } \\
\text { Horisontal (meter) }\end{array}$ & Kecepatan $(\mathbf{k m} / \mathbf{j a m})$ & Kapasitas Baterai Drone yang Digunakan $(\%)$ \\
\hline 1. & 10 & 1.424 & 9 \\
2. & 20 & 0.873 & 12 \\
3. & 30 & 3.669 & 13 \\
4. & 40 & 5.013 & 15 \\
5. & 50 & 4.818 & 9 \\
6. & 60 & 3.670 & 21 \\
7. & 70 & 4.183 & 23 \\
8. & 80 & 6.098 & 25 \\
9. & 90 & 5.082 & 17 \\
10. & 100 & 8.741 & 31 \\
\hline
\end{tabular}

Kecepatan terbang drone pada jarak terbang yang telah ditentukan tidak dilakukan secara konstan, tetapi dilakukan secara acak. Pada jarak terjauh, 100 meter, kecepatan paling tinggi, $8,741 \mathrm{~km} / \mathrm{jam}$, membutuhkan daya baterai untuk terbang sebesar $31 \%$. Hasil pengujian terbang horisontal dalam bentuk grafik dapat dilhat pada gambar 9. 


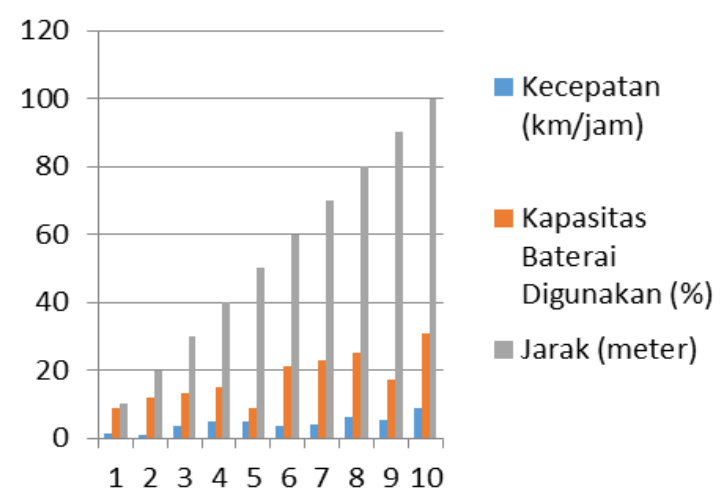

Gambar 9. Grafik hubungan jatak, kecepatan, dan kapasitas baterai dalam pengujian terbang horisontal

Pengujian selanjutnya membandingkan aplikasi Mydrone yang ada pada smartphone saat dibawa oleh drone dan menggunakan sepeda motor. Hal ini dilakukan untuk menguji pengiriman data yang dilakukan oleh Mydrone ke Admin drone melalui jaringan internet seperti pada Gambar 9. Dengan rute yang sama saat terbang menggunakan drone, smartphone yang berisi aplikasi Mydrone dibawa menggunakan sepeda motor.

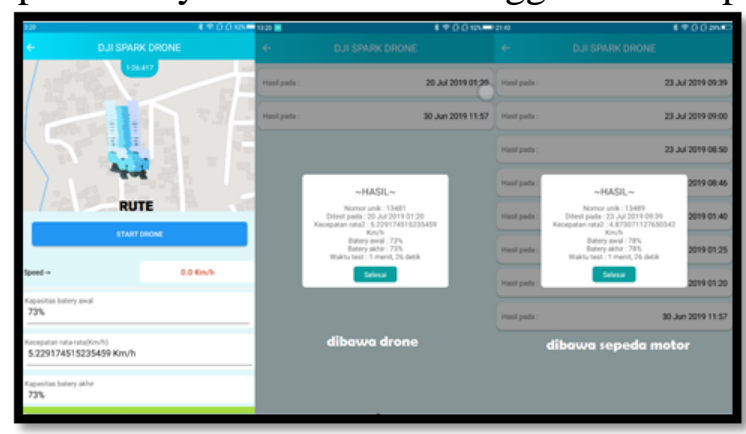

Gambar 10. Perbandingan aplikasi dibawa motor dengan dibawa drone

Hasil pengujian yang dilakukan seperti pada Gambar 10 dapat dilihat pada Tabel 2. Pada Tabel 3 dapat dilihat bahwa data mampu dikirimkan dari Mydrone ke Admin drone dengan metode client-server dengan cara dibawa oleh drone atau menggunakan sepeda motor. Ini terjadi karena adanya koneksi internet yang menghubungkan antara dua perangkat smartphone yang terhubung secara client-server.

Tabel 2. Percobaan Pengiriman Data ke Server

\begin{tabular}{clc}
\hline No & Cara membawa aplikasi & Data Berhasil Dikirim dari Client Ke Server \\
\hline 1. & Sepeda/ Sepeda Motor & $\checkmark$ \\
2. & Drone & $\checkmark$ \\
\hline
\end{tabular}

Keterangan :

1. $\checkmark$ : Berhasil

2. $\mathrm{X}$ : Gagal

Hasil pengujian dengan menggunakan sepeda motor sebagai kendaran yang membawa aplikasi Mydrone memiliki kesamaan data dengan penelitan sebelumnya tentang pengukuran kecepatan kendaraan[6]. Perbedaannya terletak pada cara melihat datanya, pada penelitian ini data yang didapat pada sisi client dikirimkan ke sisi server menggunakan jaringan internet 
sehingga kinerjanya sangat tergantung dengan keberadaan sinyal yang disediakan oleh provider telekomunikasi yang digunakan pada sisi client dan sisi server.

\section{Kesimpulan}

Berdasarkan hasil pengujian dan pembahasan yang dilakukan dapat diambil kesimpulan bahwa layanan yang ada pada Google Play Service yaitu getspeed() dapat digunakan untuk mengukur kecepatan baik diudara menggunakan drone atau didarat menggunakan sepeda motor yang bergerak secara horisontal dengan menggunakan metode client server memanfaatkan firebase data dapat dikirimkan. Selain itu kecepatan terbang drone memiliki pengaruh terhadap kapasitas baterai dari drone, sehingga perlu kajian lebih mendalam lagi terkait kapasitas baterai jika ingin sebuah drone terbang dengan kecepatan tinggi.

\section{Daftar Pustaka}

[1] Wintolo, H., Sudaryanto, S., \& Pramudito, C. G. (2018). Remote Camera For Android Based Smartphones Installed On The Syma X8HG Drone. Angkasa: Jurnal Ilmiah Bidang Teknologi, 10(2), 130-140.

[2] Wintolo, H., Kusumaningrum, A., \& Aditya, R. (2019). Pengiriman Data Koordinat Global Position System (GPS) Pada Drone Dengan Memanfaatkan Jaringan Internet. Simetris: Jurnal Teknik Mesin, Elektro dan Ilmu Komputer, 10(1), 141-146.

[3] Basukesti, A., \& Indrianingsih, Y. (2014). Sistem Pengendalian Jarak Terbang Pada Pesawat Quadcopter Untuk Menghindari Loss of Control. Teknoin, 2

[4] Hanafi, N., Miftahudin, A. M. I., Akbar, C., Ali, N., \& Dewanto, R. S. (2018). Pengendalian Kecepatan Gerak Quadcopter Berbasis IMU pada Gerakan Tangan dengan Metode Template Matching. Jurnal Rekayasa Elektrika, 14(3).

[5] Andrew, A., Buliali, J. L., \& Wijaya, A. Y. (2017). Deteksi Kecepatan Kendaraan Berjalan di Jalan Menggunakan OpenCV. Jurnal Teknik ITS, 6(2), A415-A420.

[6] Gustina, R., Setiawan, W., \& ER, N. I. Pengukuran Kecepatan Kendaraan Secara Realtime Berbasis Android. Majalah Ilmiah Teknologi Elektro, 15(1), 91-94.

[7] Prasetya, K. R. A., Setiawan, W., \& Djuni, I. K. D. Visualisasi Kecepatan Kendaraan Menggunakan Instant Messaging Berbasis Android. Majalah Ilmiah Teknologi Elektro, 15(2), 1-6.

[8] Sadewo, S. S., Sumiharto, R., \& Candradewi, I. (2015). Sistem Pengukur Kecepatan Kendaraan Berbasis Pengolahan Video. IJEIS (Indonesian Journal of Electronics and Instrumentation Systems), 5(2), 177-186.

[9] Ramdhani, A. S. (2016). Rancang Bangun Sistem Pengukur Kecepatan Kendaraan Menggunakan Sensor Magnetik (Doctoral dissertation, Universitas Pendidikan Indonesia).

[10] Sukabhakti, Y. M. N., \& Sulistyaningrum, D. R. (2019). Estimasi Kecepatan Kendaraan Bergerak Menggunakan Motion Vector. Jurnal Sains dan Seni ITS, 8(1), 7-11.

[11] Gusa, R. F. (2014). Teknik Rektifikasi Citra dan Tapis Kalman Dalam Mengestimasi Kecepatan Kendaraan. Jurnal Nasional Teknik Elektro, 3(1), 8-17.

[12] Ramadan, D. N., Permana, A. G., \& Hafidudin, H. (2017). Perancangan Dan Realisasi Mobil Remote Control Menggunakan Firebase. Jurnal Elektro dan Telekomunikasi Terapan, 4(1), 505-505.

[13] Irawan, H. (2017). Rancang Bangun Wireless Sensor Network Pada Pendeteksi Dini Potensi Kebakaran Lahan Gambut Menggunakan Banana Pi IoT (Doctoral dissertation, Institut Teknologi Sepuluh Nopember).

[14] Kartikadarma, E., Yutriatmansyah, W. W., Udayanti, E. D., \& Hafidhoh, N. U. 
Daewu Gus Bintara Putra, Anggraini Kusumaningrum

(2019). Implementasi Firebase Cloud Messaging Pada Emergency Call Berbasis Android. Simetris: Jurnal Teknik Mesin, Elektro dan Ilmu Komputer, 10(1), 83-90. 